\title{
Dockless bike-sharing system: Solving the problem of faulty bikes with simultaneous rebalancing operation
}

\author{
Muhammad Usama \\ Southeast University \\ usama@seu.edu.cn
}

\section{Yongjun Shen (corresponding author) \\ Southeast University \\ shenyongjun@seu.edu.cn}

\author{
Onaira Zahoor \\ Southeast University \\ onairakhattak@yahoo.com
}

\author{
Qiong Bao \\ Southeast University \\ baoqiong@seu.edu.cn
}

Abstract: The Free-Floating Bike-Sharing System (FFBS) enables commuters to pick up and drop off a shared bike without going to a docking station before and after the trip. However, the specific sharing features of the FFBS can also be a problem for users because randomly scattered and faulty bikes within the system can result in bike unavailability and maintenance difficulties. This not only negatively impacts the company's service quality but also causes user safety issues. In this study, a mechanism for the rebalancing of useable bikes and faulty bikes is presented in two steps: 1) gathering each faulty bike at a station determined by the model traversing the shortest path by light service vehicles; and 2) enabling the rebalancing operation to obtain optimal bike inventory levels at all stations and collect faulty bikes at a depot. The destination station from which each faulty bike is taken is considered a decision variable rather than shifting them to a closer station. The mechanism is based on minimizing the total cost of the rebalancing operation by optimizing the formulated problem, supported by time and capacity constraints. Using CPLEX solver, the validity of the model is tested through different numerical experiments.

Keywords: Dockless bike-sharing problem, faulty bike recycling problem (FBRP), rebalancing, mixed-integer programming.

\section{$1 \quad$ Introduction}

The free-floating bike-sharing system (FFBS) is gaining popularity worldwide as it is a green and socially equitable mode of transport. FFBS efficiently solves the commuters' first and last mile problem in multimodal urban transport by facilitating the user to rent a bike from the nearest location and to return at any suitable location after the ride. The bike-sharing system has grown significantly in recent decades since its introduction in 1965. As

\section{Article history:}

Received: April 15, 2019

Received in revised form:

March 26, 2020

Accepted: April 18, 2020

Available online: November 10, 2020

Copyright 2020 Muhammad Usama, Onaira Zahoor, Yongjun Shen \& Qiong Bao http://dx.doi.org/10.5198/jtlu.2020.1594

ISSN: 1938-7849 | Licensed under the Creative Commons Attribution - Noncommercial License 4.0

The Journal of Transport and Land Use is the official journal of the World Society for Transport and Land Use (WSTLUR) and is published and sponsored by the University of Minnesota Center for Transportation Studies. 
of 4 December 2018, bike-sharing systems were available in about 2,115 cities, involving more than 15 million self-service bikes around the globe (Meddin \& DeMaio, 2019). The use of FFBS has increased swiftly in China since 2016 (Ma, Zhang, \& Gao, 2017), and there are 50 million trips by bike per day (Zhang \& Mi, 2018). However, there is always deficiency or excess of sharing-bikes in the system due to uneven flows that either unable to accommodate users at some points or remain sedentary at some other points. Therefore, periodical rebalancing of bikes in the system is inevitable to fulfill the commuters' demand at all service locations within the city according to their demand level in the system. Accordingly, the shared bike operators deploy a truck fleet to solve this imbalance problem in the system. The rebalancing problem consists of two steps. First, estimating the target inventory at each station. Second, setting out the rebalancing operation plan (Schuijbroek, Hampshire, \& van Hoeve, 2017). The rebalancing operation involves routing vehicles left the depot, necessary pickups and deliveries of bikes to achieve maximum user demand at all locations and return to the depot within the prescribed time.

The presence of faulty shared-bikes in the system is another key problem. The shared-bikes may be damaged by use or willfully by convicted persons. The presence of such bikes is of great concern to the commuters, local authorities and operators. The use of such bikes poses a serious safety problem for users, and their presence causes an unpleasant appearance as well as other environmental and congestion problems. For the operators, this is a waste of available resources and has a negative impact on the quality of service.

For the bike-sharing companies, it has been challenging to replace faulty stock and to engage resources to haul bikes all the day from low-to high-demand locations (Zhong \& Zhang, 2018). The excessive supply of shared bikes resulted in piles of faulty bikes in many big cities of China (Taylor, 2018). Consequently, The Shanghai authorities have confiscated thousands of shared-bikes after being illegally parked or there were excessive numbers in some areas (Yan, 2017). In July 2017, the WukongBike became the first bankrupt bike-sharing company just after three months of its foundation. In August 2017, the Chinese central government launched the first policy, followed by many local governments' regulations, to prohibit bike-sharing companies from bringing more bikes to the market ( Hui, 2017; Yin, Qian, \& Shen, 2018). At the end of 2015, only two years after the launch of FFBS in China, a lot of unexpected adverse public outcomes happened, such as user abuse of bikes, excessive bikes on streets, and an increase in the number of faulty bikes that need to be removed (Campbell, 2018; Yin et al., 2018). In Dallas, $12 \%$ of the shared-bikes found to be damaged badly which posed a safety hazard (Lazo, n.d.). These issues make bike-sharing companies apprise of paying particular attention to the quality of bikes, as $30 \%$ of the users express low satisfaction about it with a high percentage of users complaining about non-functional bikes (Sun, 2018). Defective bikes, if not repaired quickly, users may be injured, delayed, or have bad experiences. Secondly, faulty bikes can be widespread in different parts of the city, making it a challenge and cost concerning material and manpower to quickly repair or replace them (Lan, Ma, Zhu, Mangalagiu, \& Thornton, 2017).

Therefore, along with the rebalancing of usable bikes, it is inevitable to take faulty bikes into account in order to repair and recycle them. Nonetheless, limited literature is available on faulty bikes. Alvarez-Valdes et al. (2016) was the first research to consider faulty bikes. Wang and Szeto (2018) considered usable and faulty bikes as well as investigated their environmental impacts. However, all of these studies focused on the Docked bike-sharing system and such studies are not available for FFBS. The docked bike-sharing (DBS) system differs widely from the Dockless bike-sharing system. Bikes in DBS are parked only at docking stations. During rebalancing, it is expected that both bikes, usable and faulty, should be at the docking stations. On the other hand, the docking stations have a fixed capacity. In FFBS bikes can be parked at any suitable location. In addition, cyclists leave their bikes where they observe the failure of the bike they are traveling on, and find another to end their journey. This leads to 
faulty bikes that are scattered far from the place of origin-destination. This flexibility in the use of FFBS creates a completely different and challenging scenario for sharing-bike operators to relocate usable and replace faulty bikes. To ensure a better quality of service, sharing-bike operators need an optimized mechanism to solve these problems.

Moreover, almost all the studies were conducted by assuming a predefined number of routing

trucks, and the fleet size is never optimized to achieve the minimum cost. In other words, no research has been conducted on both usable and faulty bikes with an optimized size of the routing fleet.

The main contribution of this study lies in the following: to present a mechanism for static FFBS rebalancing with faulty bikes, and to formulate the problem of both usable and faulty bikes with optimum fleet size.

The framed model can help bike-sharing companies:

i) to rebalance usable bikes in the system to obtain the target inventory levels at each station;

ii) to bring detected faulty bikes from various locations to the depot for repair;

iii) to distribute repaired bikes into the system, and

iv) to accomplish all the above objectives with an optimized operating cost.

The rest of the paper is structured as follows. Section 2 provides a brief review of past research related to shared-bike rebalancing problems. In Section 3, the designed mechanism is presented. The mathematical model is formulated in Section 4, followed by a numerical experiment and the corresponding results, and Section 6 concludes this study with future research directions.

\section{$2 \quad$ Literature review}

FFBS or dockless bike-sharing system is the fourth generation of shared-bike development $(\mathrm{Gu}, \mathrm{Kim}$, \& Currie 2019) since its first-generation "White Bike" in 1965, the coin deposit bike in 1995, and the third one developed in France in 2005 (Shaheen, Guzman, \& Zhang, 2010). The second-generation system was introduced in Beijing in 2005, third-generation in Hangzhou in 2008 and the dockless sharing-bike was introduced in 2015 (Shaheen, Zhang, Martin, \& Guzman, 2011; Sun, 2018). The bike-sharing industry in China and most of the other countries have experienced nothing short of a roller-coaster ride with the development of the internet and GPS. Unlike traditional docked bikesharing systems, FFBS is based on global positioning system (GPS) rather than on-road docking stations (Parkes, Marsden, Shasheen, \& Cohen, 2013). In this system, bikes are unlocked through a smartphone by scanning a quick response code and are picked up and dropped off at any suitable location. This flexibility of dockless bikes is comfortable for the users under different situations and has not only solved the commuters' last mile problem but also overtaken the docked bike-sharing system.

Being the sustainable mode of urban mobility in many cities of the world, the bike-sharing system is changing the mobility behavior of different road users (Fishman, 2016; Möhlmann, 2015; Shaheen \& Chan, 2016). As estimated, about 125 cities of the world had bike-sharing programs in 2010 that involved around 140,000 shared bikes (Shaheen et al., 2010). By the end of January 2019, this innovative service was available in about 2,140 cities with more than 15.6 million bikes worldwide (Meddin \& DeMaio, 2019). Instead of possession and purchase, the consumption for shared-bikes relies on the access (Yin et al., 2018).

The outspread distribution of shared-bikes not only reduces searching time but also eases distances from traveler to a bike. The users register themselves through an app while using the shared-bike for the first time, scan their identification and give a deposit. The map, after displaying all the shared-bikes around the users, locates the nearest one. After scanning a quick response code, within a few minutes the 
user can hear the click and hit on the road. The two major aspects of a bike-sharing system "operation and analysis" are the core topics for researchers (Médard de Chardon \& Caruso, 2015). The analysis mainly focuses on Spatio-temporal usage patterns of the shared-bikes and their users' safety aspects (Biehl, Ermagun, \& Stathopoulos, 2018; Borgnat et al., 2010; Caulfield, O'Mahony, Brazil, \& Weldon, 2017; Chen, Li, Wang, \& Jiang, 2018; Corcoran, Li, Rohde, Charles-Edwards, \& Mateo-Babiano, 2014; Du \& Cheng, 2018; Guo, Li, Wu, \& Xu, 2018; Ji et al., 2016; Ji, Ma, Yang, Jin, \& Gao, 2018; Jiménez, Nogal, Caulfield, \& Pilla, 2016; Montoliu, 2012; Sarkar, Lathia, \& Mascolo, 2015; Vogel, Greiser, \& Mattfeld, 2011; Wang, Xu, Xia, \& Qian, 2017; Zhang, Brussel, et al., 2018) while the main focus of the operation is on the rebalancing of bikes in the network. Rebalancing refers to the relocation of shared-bikes to improve their performance and to satisfy the user's demand in the bike-sharing system.

In the literature, many studies focused on two types of rebalancing for bike-sharing systems: static, when the system usage is negligible. This is performed during night hours, and the target is to meet the demand for the next day (e.g., Alvarez-Valdes et al., 2016; Benchimol et al., 2011; Chemla, Meunier, \& Calvo, 2013; Erdoğan, Laporte, \& Calvo, 2014; Ho \& Szeto, 2014; Usama, Zahoor, Bao, Liu, \& Shen, 2019), and the dynamic one, which focuses on daytime operation with continuously fluctuating demand when the system is in use (e.g., Contardo, Rousseau, \& Morency, 2012; Kloimüllner, Papazek, Hu, \& Raidl, 2015; Shui \& Szeto, 2018; Zhang, Yu, Desai, Lau, \& Srivathsan, 2017).

Static rebalancing operations for the bike-sharing system were first introduced by Benchimol et al. (2011) and Chemla et al. (2013). No time constraint was imposed and deviation from the target inventory levels was not allowed in the rebalancing operation. The sole objective of the study was to achieve the target inventory levels at each station with a minimum operating cost. This work was extended by Erdoğan et al. (2014) and he assumed the stations to have an inventory of bikes lying between prespecified intervals. By considering stochastic demand, Raviv, Tzur, and Forma (2013) formulated arc indexed (AI) and time indexed (TI) mixed-integer linear problem (MILP) formulations for static rebalancing. While Contardo et al., (2012) proposed a continuous bike-sharing rebalancing problem when the bike-sharing system is in use. By generating routes using the variable neighborhood search (VNS) metaheuristic algorithm, where the loading instructions were computed by an additional algorithm, Rainer-Harbach, Papazek, Hu, and Raidl (2013) proposed a heuristic approach for the rebalancing bike-sharing system.

However, the focus of all these studies was docked bike-sharing systems and very few researchers have studied rebalancing of FFBS. Pal and Zhang (2017) formulated a static rebalancing problem using multiple vehicles for FFBS to obtain an optimal inventory level with minimum routing cost. By extending the FFBS rebalancing problem, Liu, Ying, Szeto, and Ho (2018) introduced a unique feature for the inconvenience level of getting a bike from FFBS. He defined two types of nodes based on the user convenience level, and the problem was formulated as a multiple-vehicle static rebalancing problem. A comprehensive formulation was presented in this study, but a predefined number of vehicles was deputed for the rebalancing.

All these studies solved the rebalancing problem but rarely considered the faulty bikes presented in the system. Faulty bikes are always found in the system, and they not only cause user dissatisfaction but also result in users' safety issues. Besides, the negative impact of having faulty resources is to provide users with misleading information (Kaspi, Raviv, \& Tzur, 2016; Kaspi, Raviv, \& Tzur, 2017). Therefore, it is necessary to consider faulty bikes shifting to depot along with rebalancing of usable bikes and repaired bikes distribution into the system. However, very limited studies are available on faulty bikes. AlvarezValdes et al. (2016) is the first paper considering damaged bikes along with rebalancing while optimizing the level of service quality. A Bayesian model was proposed by Kaspi et al. (2016) for detecting damaged 
bikes in the docked bike-sharing system. Wang and Szeto (2018) conducted a comprehensive study by considering usable, damaged bikes and environmental impacts simultaneously.

The focus of all these studies was faulty bikes or damaged lockers of the docked bike-sharing system, and no study put light on FFBS. In a study by Chang, Song, He, and Qiu (2018) a framework was designed for faulty sharing-bikes recycling problem but it considered the situation of only faulty bikes in the system. This study has a very limited scope and needs separate routing operation for the usable bikes' rebalancing to cater to users' dissatisfaction. This will not only increase the routing cost but also have negative environmental and traffic congestion issues for systems in big cities. Besides, faulty bikes are collected at the centroids determined by the algorithm that might be a physically inaccessible point, which is the key point for the routing operation. The docked bike-sharing system differs from FFBS; therefore, it needs further studies to solve the issue of faulty bikes presented in the system. Usama et al. (2019) and Usama, Shen, and Zahoor (2019) proposed formulation for rebalancing FFBS with faulty bikes using battery-electric and internal combustion engine vehicles, respectively. However, these studies did not take the handling of faulty bikes to their suitable neighboring stations.

Table 1 summarizes the differences among some currently available studies on static shared-bike rebalancing problems and the main focus of this study.

Table 1. Summary of the characteristics of the static rebalancing problems in the literature

\begin{tabular}{|c|c|c|c|c|c|c|}
\hline References & FFBS & DBS & $\begin{array}{l}\text { Multiple } \\
\text { vehicles }\end{array}$ & $\begin{array}{r}\text { Faulty } \\
\text { bikes }\end{array}$ & Fleet size & $\begin{array}{l}\text { Handling } \\
\text { length }\end{array}$ \\
\hline Benchimol et al. (2011) & & $\checkmark$ & & & & \\
\hline Chemla et al. (2013) & & $\checkmark$ & & & & \\
\hline $\begin{array}{l}\text { Dell'Amico, Hadjicostantinou, Lori, and Novel- } \\
\text { lani (2014) }\end{array}$ & & $\checkmark$ & $\checkmark$ & & & \\
\hline Ho and Szeto, (2014) & & $\checkmark$ & & & & \\
\hline Alvarez-Valdes et al. (2016). & & $\checkmark$ & $\checkmark$ & $\checkmark$ & & \\
\hline Liu et al. (2018) & $\checkmark$ & & $\checkmark$ & & & \\
\hline Pal and Zhang (2017) & $\checkmark$ & & $\checkmark$ & & & \\
\hline Zhang, Xiang, et al. (2018) & & $\checkmark$ & $\checkmark$ & $\checkmark$ & & \\
\hline Wang and Szeto (2018) & & $\checkmark$ & $\checkmark$ & $\checkmark$ & & \\
\hline Usama et al. (2019) & $\checkmark$ & & $\checkmark$ & $\checkmark$ & & \\
\hline This Study & $\checkmark$ & & $\checkmark$ & $\checkmark$ & $\checkmark$ & $\checkmark$ \\
\hline
\end{tabular}




\section{Dockless bike sharing rebalancing with faulty bikes}

Scheming bike-sharing rebalancing with faulty bikes makes it intelligible for bike-sharing companies to oversee the issue of the faulty bike. Bike-sharing companies often experience difficulties in allocating and collecting faulty bikes. In the following Sections, a proposed mechanism is presented for rebalancing FFBS with faulty bikes.

\subsection{Faulty bike identification}

The faulty bikes can be detected in several ways. This paper describes four scenarios for a bike to be taken as a faulty bike:

- User feedback: The bike-sharing smartphone applications has the facility to report the current status of a bike. When a user unlocks a bike and finds it unusable and communicates its status with the server through the application's failure reporting menu. A failure reporting interface of the HelloBike app is shown in Figure 1.

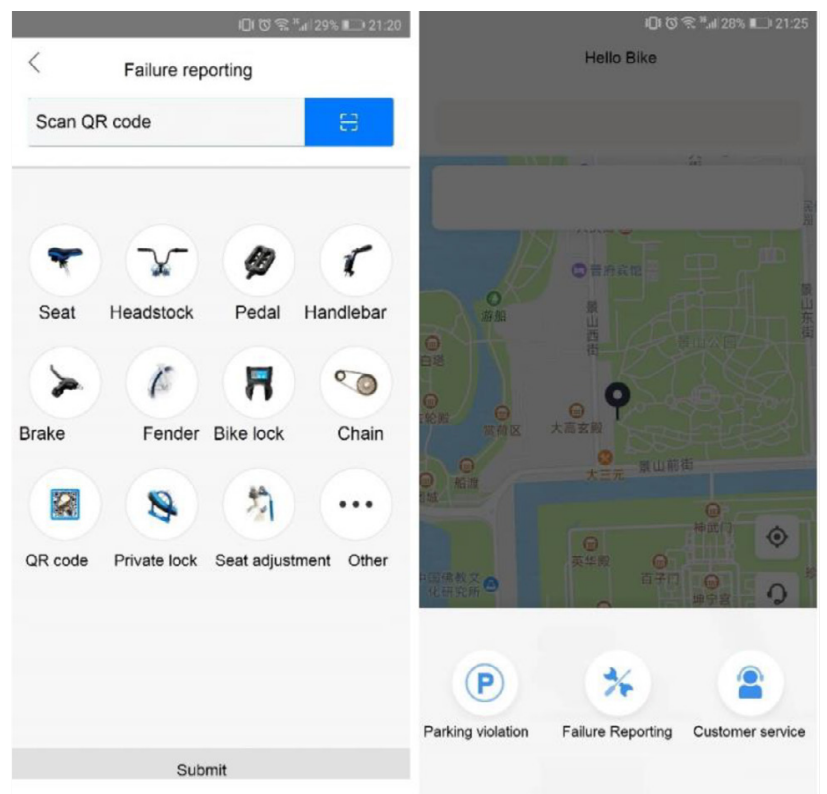

Figure 1. A screenshot image for reporting a faulty bike in HelloBike's app

- Lost location: When a bike's GPS equipment stops working due to some fault, and it is disconnected from the system, the server saves it as a faulty bike from its last location.

- Inactive: Bikes remain unused for more than 24 hours, which means it is either faulty or improperly parked.

- Service life: A bike completed its design life and is forced to scrap.

- The location data of the identified faulty bikes are used as input to the rebalancing problem. 


\subsection{Route optimization}

Two types of the fleet are assumed in this part: the service vehicles and the rebalancing routing vehicles. The service vehicles are tri-wheeled light vehicles that will gather faulty bikes to various stations as illustrated in Figure 2. The required number of service vehicles will visit each faulty bike, and its operator will shift it to a station determined by the mathematical model in Section 4. The shifting of scattered faulty bikes to their nearest stations will certainly reduce handling cost. However, shifting of a faulty bike to its closer station does not guarantee an optimum solution. Especially, when a closer station has already optimal bike inventory, and the rebalancing truck purely visits that station to pick up a faulty bike. Consequently, the total cost of the rebalancing operation increases. Therefore, to optimize the total cost, it is necessary to consider the destination station of each faulty bike as a decision variable.
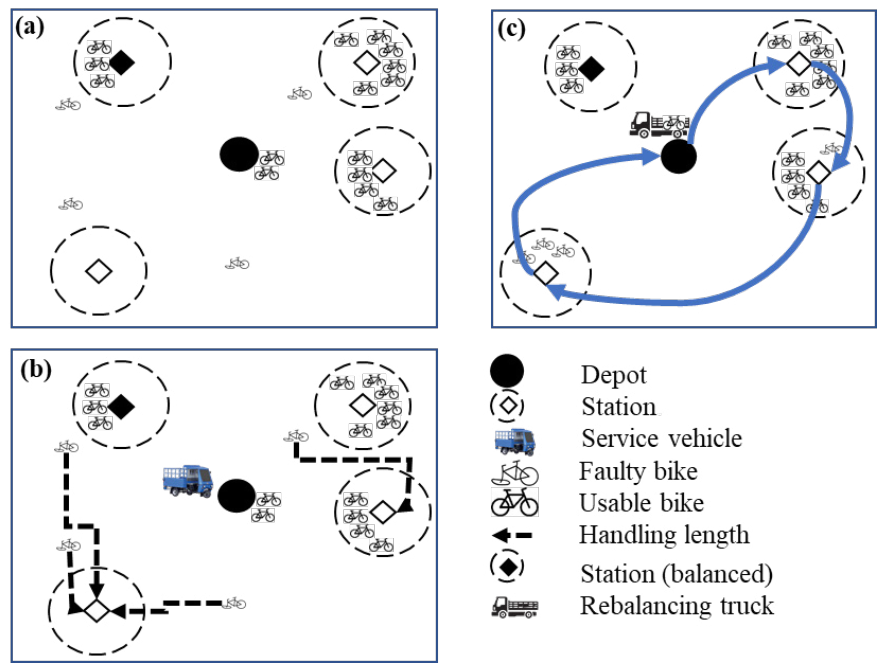

Figure 2. (a) depot, stations, repaired, present, inventory at the stations, and faulty bikes at scattered locations in the system; (b) faulty bikes handling to various stations determined by the model using a light service vehicle; (c) the rebalancing truck routing to balance usable, distribute repaired and pick up faulty bikes following an optimized solution

The rebalancing routing vehicles are a fleet of heterogeneously capacitated trucks that are planned to visit all the stations under certain constraints traversing optimal paths obtained from the solution of the formulated rebalancing problem.

\subsection{Operation}

After having all the information from previous steps, the routing vehicles will perform rebalancing operation with simultaneous faulty bike loading to the depot.

\section{$4 \quad$ Mathematical modelling}

In this section, we will present a mathematical formulation based on the mechanism described in Section 3. It consists of two major steps: a) gathering faulty bikes by the service vehicles, defined in Section 3.1 , to the station where the total rebalancing operation cost is minimized, and b) rebalancing vehicles route optimization, it consists of following tasks: i) distribution of repaired bikes from the depot to other 
stations, ii) rebalancing of useable bikes at different stations by the rebalancing vehicles, and iii) faulty bikes gathering to the depot from the other stations.

The rebalancing problem with faulty bikes is formulated based on the following assumptions:

1. the location of a faulty bike is accurate;

2. a service vehicle will visit each faulty bike and shift these bikes to the various stations before the departure of rebalancing vehicle from the depot; and

3. there is only one depot, $\mathrm{O}$, from where the rebalancing vehicles will start and end their routes.

The following set, parameters and decision variables are used to formulate the problem.

\begin{tabular}{|c|c|}
\hline \multicolumn{2}{|l|}{ Sets } \\
\hline$s$ & Set of all stations other than the depot. \\
\hline$s_{o}$ & Set of all stations including the depot $s_{\mathrm{o}}=s \cup O$. \\
\hline$K$ & Set of heterogeneous rebalancing vehicles $K=\left\{k_{1}, \ldots, k_{n}\right\}$. \\
\hline$f_{b}$ & Location of faulty bike $b \in\{1, \ldots, F b\}$ \\
\hline$\left[d_{i}^{l}, d_{i}^{u}\right]$ & Lower and upper bound of bikes demand at station $i \in S$. \\
\hline \multicolumn{2}{|c|}{ Parameters } \\
\hline$b_{i}^{o}$ & Number of usable bikes before rebalancing operation at station $i \in S_{o}$ \\
\hline$\lambda$ & a cost factor on bikes for their deviation from the target demand interval. \\
\hline$F_{b}$ & Total number of faulty bikes in the network. \\
\hline$t^{b}$ & Service vehicle travel time in minutes from the location of faulty bike $i \in f b$ to a station $j \in S$. \\
\hline$t_{i j}$ & Rebalancing truck traveling time in minutes from station to $i$ to $j(i, j) \in S_{o}$. \\
\hline$Q_{k}$ & Loading carrying capacity of rebalancing truck $k \in K$ \\
\hline$\ell$ & Loading time of a bike onto rebalancing truck $k \in K$. \\
\hline$\mu$ & Unloading time of a bike from rebalancing truck $k \in K$. \\
\hline$\xi_{s}$ & Operational cost per minute of handling a faulty bike from its location to station. \\
\hline$\xi_{t}$ & Operational cost of rebalancing truck per minute \\
\hline$T$ & Time span of rebalancing operation in minutes \\
\hline$M$ & An upper bound over all paths in vehicle tour, a big number. \\
\hline \multicolumn{2}{|c|}{ Decision Variables } \\
\hline$x_{i j k}$ & Binary variable $=1$, if a rebalancing truck traverses from station $i$ to $j ;(i, j) \in s_{o}, 0$ otherwise. \\
\hline$x^{b}{ }_{i j}$ & Binary variable $=1$, if a faulty bike $i \in f b$ is shifted to a station $j \in S_{o}, 0$ otherwise. \\
\hline$y_{k i}$ & Binary variable $=1$, if a rebalancing truck $k \in K$ serves station $i \in s_{o}, 0$ otherwise. \\
\hline$b_{i}$ & Usable bike inventory level at station $i \in S_{o}$ after rebalancing operation. \\
\hline$f_{i}^{n}$ & Number of faulty bikes collected at station $i \in S_{o}$ \\
\hline$y_{i k}^{l f}$ & Number of faulty bikes loaded onto rebalancing truck $k \in K$ at station $i \in S$. \\
\hline$y_{i k}^{l}$ & Number of usable bikes picked up by a rebalancing truck $k \in K$ at station $i \in S_{o}$. \\
\hline$y_{i k}^{u}$ & Number of useable bikes dropped off from the rebalancing truck at station $i \in S_{o}$. \\
\hline$y_{i j k}^{f}$ & Number of faulty bikes carried by the rebalancing truck $k \in K$ travelling from $i$ to $j ;(i, j) \in S_{o}$. \\
\hline$y_{i j k}^{r}$ & Number usable bikes carried by the rebalancing truck $k \in K$ travelling from $i$ to $j ;(i, j) \in s_{o}$. \\
\hline$\phi_{i}$ & Supplementary variable related to station $\mathrm{i} \in S$ with user dissatisfaction to unmet demand. \\
\hline$U_{i k}$ & A variable defined for rebalancing truck subtour elimination, $k \in K, i \in S_{0}$. \\
\hline
\end{tabular}


After defining sets, parameters and decision variables, rebalancing truck routing problem with faulty bikes is presented.

$$
\begin{aligned}
\min z= & \lambda \sum_{i \in S} \phi_{i} \\
& +\xi_{t} \sum_{k \in K}\left(\sum_{i \in s_{o}} \sum_{j \in s_{o}} t_{i j} x_{i j k}+\sum_{i \in S}\left(\ell\left(\mathrm{y}_{i k}^{l}+y_{i k}^{l f}\right)+\mu \cdot y_{i k}^{u}\right)\right) \\
& +\xi_{s} \sum_{i \in f_{b}} \sum_{j \in S} t_{i j}^{b} x_{i j}^{b}
\end{aligned}
$$

The objective function (1) minimizes the following objectives: i) user dissatisfaction to unmet demand at any station, ii) rebalancing truck routing cost including bikes loading, unloading cost, and iii) handling length of faulty bikes.

$$
\sum_{j \in s} x_{i j}^{b}=1 \quad \forall i \in f_{b}
$$

Constraint (2) ensures the gathering of each faulty bikes to any suitable station.

$$
\begin{array}{ll}
\sum_{i \in f_{b}} \sum_{j \in S} x_{i j}^{b}=F_{b} & \\
\sum_{i \in f_{b}} x_{i j}^{b}=f_{j}{ }^{n} & \forall j \in S
\end{array}
$$

Gathering of all the faulty bikes is confirmed through constraint (3), and (4) gives the number of faulty bikes collected at each station.

$$
\sum_{k \in K} y_{k i} \leq 1 \quad \forall i \in S
$$

Constraint (5) guides the rebalancing routing trucks to visit a station at most once. This flexibility permits the routing truck to omit the stations where the present usable bikes inventory is within the demand interval.

$$
\sum_{k \in K} y_{k i} \leq|K| \quad \forall i \in O
$$

Constraint (6) limits the number of trucks leaving the depot to the available fleet size.

$$
\begin{array}{lr}
\sum_{j \in s_{o}} x_{j i k}=y_{k i} & \forall i \in S, k \in K \\
\sum_{j \in s_{0}} x_{i j k}=y_{k i} & \forall i \in s_{o}, k \in K
\end{array}
$$


Constraints (7) and (8) ensure continuity of the routes.

$x_{i j k}=\mathrm{y}_{i j k}^{r}=y_{i j k}^{f}=y_{i j k}^{t}=0 ; \quad \forall i, j \in s_{o}: i=j, k \in K$

Constraint (9) eliminates invalid arcs and sets bike load of rebalancing truck to zero on them.

$y_{i k}^{l f}=f_{i}^{n} \quad \forall i \in s, k \in K$

Constraint (10) forces loading all the faulty bikes into rebalancing truck gathered at various stations.

$$
\begin{array}{ll}
\sum_{k \in K} y_{i k}^{l f}=0 & \forall i \in O \\
\sum_{j \in s_{0}} \sum_{k \in K} y_{i j k}^{f}=F_{b} & \forall i \in O
\end{array}
$$

Constraint (11) prohibits the loading of faulty bikes from the depot and (12) forces gathering all faulty bikes at the depot after the rebalancing operation.

$$
b_{i}=b_{i}^{o}-\sum_{k \in K}\left(y_{i k}^{l}-y_{i k}^{u}\right) \quad \forall i \in S
$$

Constraint (13) guarantees inventory conservation of usable bikes at each station.

$$
\begin{array}{ll}
\sum_{k \in K} y_{i k}^{l} \leq b_{i}^{o} & \forall i \in S \\
\sum_{k \in K} y_{i k}^{l}=b_{i}^{o} & \forall i \in O
\end{array}
$$

Constraint (14) limits the loading of usable bikes to the maximum available bikes at each station, and (15) imposes that all repaired bikes should be loaded onto the rebalancing trucks for their distribution in the network.

$U_{j k} \geq U_{i k}+1-M\left(1-x_{i j k}\right) \quad \forall i \in s_{o}, j \in s, k \in K$

Constraint (16) ensures subtour elimination.

$$
\begin{aligned}
& \sum_{i \in s_{o}} y_{j i k}^{f}-\sum_{i \in s_{o}} y_{i j k}^{f}=y_{i k}^{l f} \quad \forall j \in s, k \in K \\
& y_{i k}^{l}-y_{i k}^{u}=\sum_{j \in s_{o}} y_{i j k}^{r}-\sum_{j \in s_{o}} y_{j i k}^{r} \quad \forall i \in s_{o}, k \in K
\end{aligned}
$$

The conservation of faulty and usable bikes inventory carried by the rebalancing trucks is ensured by constraints (17) and (18), respectively. 


$$
\sum_{i \in S_{o}}\left(y_{i k}^{l}-y_{i k}^{u}\right)=0 \quad \forall k \in K
$$

Constraint (19) ensures that all the loaded usable bikes should also be delivered in the network.

$$
\begin{array}{ll}
y_{i j k}^{f}+y_{i j k}^{r} \leq Q_{k} \cdot x_{i j k} & \forall i, j \in s_{o}, k \in K \\
y_{i j k}^{f}+y_{i j k}^{r}=y_{i j k}^{t} & \forall i, j \in s_{o}, k \in K
\end{array}
$$

Constraint (20) is capacity constraint of the rebalancing truck, and (21) gives the total load carried by truck at each path.

$$
y_{i k}^{u}=0 \quad \forall i \in O, k \in K
$$

Unloading of usable bikes at a depot is restricted through constraint (22).

$$
\sum_{i \in s_{o}} \sum_{j \in s_{o}} t_{i j} \cdot x_{i j k}+\sum_{i \in s_{o}}\left(\ell\left(y_{i k}^{l}+y_{i k}^{l f}\right)+\mu \cdot y_{i k}^{u}\right) \leq T \quad \forall k \in K
$$

Constraint (23) limits the total operation time of rebalancing trucks.

$$
\begin{array}{ll}
\phi_{i} \geq d_{i}^{l}-b_{i} & \forall i \in S \\
\phi_{i} \geq b_{i}-d_{i}^{u} & \forall i \in S
\end{array}
$$

The deviation of obtained inventories from the target interval is estimated through constraints (24) and (25).

$$
\sum_{i \in S} \sum_{k \in K} y_{i j k}^{r}=b_{i}^{o} \quad \forall i \in O
$$

Constraint (26) limits the load of rebalancing trucks to available repaired bikes while leaving a depot.

$$
\begin{array}{ll}
y_{i k}^{l} \geq 0 ; y_{i k}^{u} \geq 0 ; U_{i k} \geq 0 & \forall i \in s_{o}, k \in K \\
y_{i j k}^{r} \geq 0 ; y_{i j k}^{f} \geq 0 ; y_{i j k}^{t} \geq 0 & \forall i, j \in s_{o}, k \in K \\
y_{i j k}^{r} \geq 0 ; y_{i j k}^{f} \geq 0 ; y_{i j k}^{t} \geq 0 & \forall i, j \in s_{o}, k \in K \\
\phi_{i} \geq 0 & \forall i \in S
\end{array}
$$

Constraints (27)-(30) define the real domain. 


\section{$5 \quad$ Numerical experiment and results}

The model formulated in the previous section is validated through numerical experiments using IBMIlog CPLEX 12.8 on an i5 8500 @ 3.0 GHz with 8 GB of RAM.

\subsection{Data description}

The first problem consisting of fifteen shared-bike stations and one depot in Nanjing, China. The number of present and the next day demand interval of usable bikes at each station is taken randomly and presented in Table 2. The station "O" represents depot. The ten bikes at depot "O" denote the number of repaired bikes collected as faulty bikes in the previous days. The rebalancing vehicles will distribute these bikes into the system as usable bikes. Ten faulty bikes are considered at various randomly selected locations within the network. These faulty bikes are scattered in the study area and assigned to the station where it minimizes the total cost of the rebalancing operation as defined in the objective function in Equation (1). The light tri-wheeled service vehicles are used to collect these faulty bikes. The shortest travelling paths between each station are retrieved using OpenStreetMap implemented in Python 3.7 using OSMnx and NetworkX packages. The route lengths between each station and between each station to all faulty bikes are obtained from the shortest paths. The operational speed of the rebalancing vehicle and the light service vehicle is assumed to be $20 \mathrm{~km} / \mathrm{h}$ and $5 \mathrm{~km} / \mathrm{h}$, respectively. This is the average speed including bikes loading, unloading and vehicles' parking time at various stations in the network. The corresponding travel time matrix obtained for the stations and faulty bikes are presented in Table 3 and Table 4, respectively.

Table 2. The number of present bikes and the next day demand interval at each station

\begin{tabular}{|c|c|c|c|c|}
\hline Station I.D & Initial bikes inventory & Next day demand interval & Bike Deficiency & Bike Excess \\
\hline Depot "O" & 10 & {$[0,0]$} & 0 & 10 \\
\hline 1 & 6 & {$[10,15]$} & 4 & 0 \\
\hline 2 & 16 & {$[15,20]$} & 0 & 0 \\
\hline 3 & 18 & {$[22,26]$} & 4 & 0 \\
\hline 4 & 20 & {$[10,15]$} & 0 & 5 \\
\hline 5 & 9 & {$[14,18]$} & 5 & 0 \\
\hline 6 & 14 & {$[19,23]$} & 5 & 0 \\
\hline 7 & 5 & {$[10,15]$} & 5 & 0 \\
\hline 8 & 3 & {$[9,15]$} & 6 & 0 \\
\hline 9 & 20 & {$[10,15]$} & 0 & 5 \\
\hline 10 & 17 & {$[8,10]$} & 0 & 7 \\
\hline 11 & 21 & {$[12,15]$} & 0 & 6 \\
\hline 12 & 17 & {$[10,13]$} & 0 & 4 \\
\hline 13 & 5 & {$[10,14]$} & 5 & 0 \\
\hline 14 & 5 & {$[10,12]$} & 5 & 0 \\
\hline 15 & 12 & {$[10,15]$} & 0 & 0 \\
\hline Total & 198 & - & 39 & 37 \\
\hline
\end{tabular}


The capacity of the rebalancing routing vehicle is set to be 20 bikes. The operational cost per minute of the rebalancing vehicle $\xi_{\mathrm{t}}$, and light service vehicle $\xi_{\mathrm{s}}$, are selected as 6 and $0.5 \mathrm{RMB}$ respectively following the study of Chang et al., 2018. The loading $\ell$, and unloading time $\mu$, of the usable and faulty bike is set to be one minute for each bike. It is assumed that the sufficient number of rebalancing trucks is present at the depot.

Table 3. The shortest travel time in minutes between each station retrieved from OpenStreetMap using Python 3.7 with an average speed of $20 \mathrm{~km} / \mathrm{h}$

\begin{tabular}{lllllllllllllllll}
\hline $\begin{array}{l}\text { Station } \\
\text { ID }\end{array}$ & $\mathbf{O}$ & $\mathbf{1}$ & $\mathbf{2}$ & $\mathbf{3}$ & $\mathbf{4}$ & $\mathbf{5}$ & $\mathbf{6}$ & $\mathbf{7}$ & $\mathbf{8}$ & $\mathbf{9}$ & $\mathbf{1 0}$ & $\mathbf{1 1}$ & $\mathbf{1 2}$ & $\mathbf{1 3}$ & $\mathbf{1 4}$ & $\mathbf{1 5}$ \\
\hline $\mathrm{O}$ & 0.0 & 1.0 & 3.3 & 3.3 & 5.1 & 1.4 & 2.2 & 4.9 & 3.9 & 3.1 & 3.3 & 3.0 & 3.3 & 2.2 & 3.3 & 3.7 \\
1 & 1.0 & 0.0 & 2.8 & 4.2 & 5.8 & 2.3 & 3.1 & 4.0 & 3.0 & 2.1 & 4.0 & 2.0 & 4.3 & 3.1 & 4.3 & 2.8 \\
2 & 3.4 & 2.9 & 0.0 & 6.1 & 3.0 & 4.7 & 4.0 & 2.2 & 4.7 & 5.0 & 1.2 & 4.9 & 5.0 & 2.7 & 6.0 & 3.6 \\
3 & 3.2 & 4.2 & 6.0 & 0.0 & 5.4 & 1.9 & 2.3 & 7.7 & 4.7 & 3.9 & 4.9 & 3.7 & 3.4 & 3.3 & 2.4 & 5.8 \\
4 & 5.1 & 5.8 & 3.1 & 5.4 & 0.0 & 6.5 & 3.1 & 5.2 & 7.6 & 7.9 & 2.0 & 7.8 & 2.0 & 3.0 & 3.0 & 6.5 \\
5 & 1.5 & 2.3 & 4.7 & 2.0 & 6.5 & 0.0 & 3.6 & 5.8 & 2.8 & 1.9 & 4.7 & 1.8 & 4.7 & 3.6 & 4.2 & 3.9 \\
6 & 2.1 & 3.0 & 3.9 & 2.3 & 3.1 & 3.5 & 0.0 & 5.9 & 5.9 & 5.1 & 2.8 & 5.0 & 1.2 & 1.3 & 2.0 & 5.0 \\
7 & 4.6 & 3.6 & 2.2 & 7.9 & 5.2 & 5.9 & 5.9 & 0.0 & 3.9 & 4.8 & 3.3 & 5.7 & 7.0 & 4.6 & 7.9 & 2.8 \\
8 & 2.2 & 1.2 & 4.0 & 4.7 & 7.0 & 2.8 & 4.3 & 3.9 & 0.0 & 0.9 & 5.2 & 2.4 & 5.5 & 4.3 & 5.6 & 1.1 \\
9 & 2.9 & 1.9 & 4.7 & 3.9 & 7.7 & 2.0 & 5.0 & 4.7 & 0.8 & 0.0 & 5.8 & 1.6 & 6.2 & 5.0 & 6.1 & 2.0 \\
10 & 3.2 & 4.0 & 1.2 & 5.0 & 1.9 & 4.6 & 2.8 & 3.4 & 5.7 & 6.0 & 0.0 & 5.9 & 3.9 & 1.6 & 4.8 & 4.6 \\
11 & 4.3 & 3.3 & 6.1 & 5.0 & 9.1 & 3.0 & 6.4 & 6.6 & 3.2 & 2.4 & 7.3 & 0.0 & 7.6 & 6.4 & 6.8 & 4.4 \\
12 & 3.3 & 4.2 & 5.0 & 3.4 & 2.0 & 4.7 & 1.3 & 7.0 & 7.1 & 6.3 & 3.9 & 6.2 & 0.0 & 2.4 & 1.0 & 6.2 \\
13 & 2.2 & 3.1 & 2.6 & 3.4 & 3.0 & 3.6 & 1.3 & 4.6 & 5.7 & 5.2 & 1.6 & 5.1 & 2.4 & 0.0 & 3.2 & 4.6 \\
14 & 3.3 & 4.3 & 5.9 & 2.4 & 3.0 & 3.8 & 2.0 & 7.9 & 6.6 & 5.7 & 4.8 & 5.6 & 1.0 & 3.2 & 0.0 & 6.9 \\
15 & 3.4 & 2.3 & 3.5 & 5.8 & 6.5 & 3.9 & 4.8 & 2.8 & 1.1 & 2.0 & 4.6 & 3.6 & 5.9 & 3.8 & 6.7 & 0.0 \\
\hline
\end{tabular}


Table 4. The travel time in minutes between each faulty bike to all the stations retrieved from OpenStreetMap using Python 3.7 with an average speed of $5 \mathrm{~km} / \mathrm{h}$

\begin{tabular}{|c|c|c|c|c|c|c|c|c|c|c|c|c|c|c|c|}
\hline \multirow{2}{*}{ Bike ID } & \multicolumn{15}{|c|}{ Stations } \\
\hline & 1 & 2 & 3 & 4 & 5 & 6 & 7 & 8 & 9 & 10 & 11 & 12 & 13 & 14 & 15 \\
\hline 1 & 1 & 5 & 15 & 12 & 20 & 7 & 7 & 21 & 17 & 13 & 14 & 13 & 12 & 8 & 12 \\
\hline 2 & 6 & 2 & 10 & 18 & 22 & 11 & 14 & 14 & 13 & 10 & 14 & 10 & 19 & 11 & 19 \\
\hline 3 & 7 & 4 & 7 & 20 & 19 & 12 & 12 & 12 & 11 & 13 & 12 & 12 & 17 & 8 & 20 \\
\hline 4 & 11 & 15 & 21 & 7 & 15 & 13 & 5 & 29 & 24 & 20 & 17 & 20 & 7 & 10 & 3 \\
\hline 5 & 5 & 9 & 8 & 18 & 15 & 11 & 9 & 16 & 19 & 17 & 8 & 17 & 13 & 4 & 17 \\
\hline 6 & 17 & 21 & 19 & 18 & 7 & 23 & 9 & 27 & 31 & 29 & 15 & 29 & 4 & 8 & 8 \\
\hline 7 & 12 & 8 & 19 & 16 & 31 & 8 & 20 & 21 & 8 & 5 & 24 & 7 & 25 & 20 & 25 \\
\hline 8 & 9 & 5 & 16 & 13 & 28 & 5 & 18 & 18 & 8 & 4 & 21 & 4 & 22 & 18 & 22 \\
\hline 9 & 16 & 19 & 8 & 17 & 5 & 21 & 8 & 17 & 26 & 27 & 3 & 27 & 12 & 8 & 16 \\
\hline 10 & 15 & 11 & 5 & 28 & 16 & 20 & 19 & 5 & 16 & 19 & 9 & 19 & 23 & 14 & 27 \\
\hline
\end{tabular}

\subsection{Results and discussion}

The total operational cost of the rebalancing operation with faulty bikes is minimized by solving the problem defined through (1) to (30). Using sets and parameters defined above, the problem is solved using IBM-Ilog CPLEX 12.8 with default settings on an 58500 @ $3.0 \mathrm{GHz}$ with 8 GB of RAM. The model is run for a maximum of ten minutes and results are presented.

The effect of the following factors on the rebalancing operation is investigated in the following section, including:

1. The effect of the penalty against the unfulfilled demand of usable bikes $(\lambda)$

2. The effect of the time span of rebalancing operation $(\mathrm{T})$

3. The effect of the bikes carrying capacity of the rebalancing truck (Q)

4. The effect of the percentage presence of faulty bikes in the system

5. The effect of shifting faulty bikes to closer stations

\subsubsection{The effect of the penalty against the unfulfilled demand of usable bikes}

The penalty cost against the unmet demand effectively controls the excess or shortage of the usable bikes beyond the optimal inventory intervals at every station. Besides, it has a significant effect on the travelling pattern of rebalancing trucks. The problem is solved for various levels of penalty factors using one rebalancing truck and the results are presented in Table 5. 
Table 5. The usable bikes shortage and optimal routes for different penalty level $(\lambda)$

\begin{tabular}{|c|c|c|c|c|c|c|c|}
\hline$\lambda$ & HL (km) & Best route & Truckload & $\begin{array}{c}\text { Usable bike } \\
\text { shortage }\end{array}$ & CPU time (sec) & $\begin{array}{l}\text { TTT } \\
(\min )\end{array}$ & $\begin{array}{c}\text { Opt. } \\
\text { Gap (\%) }\end{array}$ \\
\hline 0 & 8.3 & $\mathrm{O}-1-\mathrm{O}$ & $10-10$ & 63 & 0.27 & 32 & 0.01 \\
\hline 5 & 6.5 & O-5-1-O & 10-6-10 & 57 & 0.3 & 34.7 & 0.01 \\
\hline 10 & 3.8 & $\begin{array}{r}\text { O-6-13-10-4-12- } \\
14-3-5-11-9-8- \\
1-O\end{array}$ & $\begin{array}{r}10-5-0-7-11-16- \\
12-9-5-11-17- \\
12-10\end{array}$ & 8 & 0.81 & 99.5 & 0.01 \\
\hline 20 & 3.4 & $\begin{array}{r}\text { O-6-13-10-4-12- } \\
14-3-5-11-9-8-15- \\
7-1-\mathrm{O}\end{array}$ & $\begin{array}{r}10-5-0-7-12-17- \\
13-10-6-13-19-14- \\
17-13-10\end{array}$ & 0 & 0.91 & 115.8 & 0.01 \\
\hline 50 & 3.4 & $\begin{array}{r}\text { O-6-13-10-4-12- } \\
14-3-5-11-9-8-15- \\
7-1-\mathrm{O}\end{array}$ & $\begin{array}{r}10-5-0-7-12-17- \\
13-10-6-13-19-14- \\
17-13-10\end{array}$ & 0 & 0.83 & 115.8 & 0.01 \\
\hline
\end{tabular}

The results show that the penalty factor has a direct effect on the shortage of bikes in the network. The constraints in the formulation allow the rebalancing trucks to visit a station at most once by all the vehicles. This flexibility in the routing constraints permits the routing truck to omit the stations where the present usable bikes inventory is within the demand interval. However, this flexibility results in the omission of the majority of the station, when no penalty is enforced against the shortage of bikes. With the small increase in $\lambda$-value, the shortage of usable bikes reduces. When $\lambda$-value is increased to 20 , optimal usable bikes inventories are obtained at all the stations.

Besides, when no penalty is imposed, the faulty bikes start converging to a single station, which results in longer handling distances. With $\lambda$-value equal to 20 , the handling length of the faulty bikes reduces $59 \%$ along with the optimal inventories at all the stations.

\subsubsection{The effect of rebalancing operation time span ( $\mathrm{T})$}

With zero tolerance in the target demand, the problem is solved for various rebalancing operation time span (T) and the results are presented in Table 6. For a shorter span, more number of vehicles are required to fulfill the target demand at each station. At first, when one truck is not sufficient to with the specified limitations, the following vehicle is added until a feasible solution with an optimized fleet size. The number of vehicles reduced to at least one from 5 vehicles when the time span is expanded from 30 to 120 minutes. Besides an increase in the number of trucks, the total traveling time of all trucks increased continuously for abbreviating time spans. Moreover, the truck use becomes inefficient as the maximum load on the routing trucks has decreased for a shorter span because of the shorter trips of a large fleet. 
Table 6. The optimal routes and fleet size under different operation time span

\begin{tabular}{|c|c|c|c|c|}
\hline Time Limit (min) & Truck Used & Routes & Truckload & $\begin{array}{c}\text { Total Time of all } \\
\text { Trucks (min) }\end{array}$ \\
\hline \multirow[t]{5}{*}{30} & 5 & $0-11-3-1-0$ & $2-8-4-0$ & 138.3 \\
\hline & & $0-12-14-0$ & $0-8-7$ & \\
\hline & & $0-5-9-8-0$ & $5-0-6-1$ & \\
\hline & & $0-4-7-0$ & $0-5-1$ & \\
\hline & & $0-10-13-6-0$ & $3-10-5-1$ & \\
\hline \multirow[t]{3}{*}{45} & 3 & $0-3-11-9-8-5-0$ & $4-0-6-11-5-0$ & 126.1 \\
\hline & & $0-13-4-12-14-6-0$ & $5-0-5-10-5-0$ & \\
\hline & & $1-10-2-7-1-0$ & $1-11-13-11-10$ & \\
\hline \multirow[t]{2}{*}{60} & 2 & $0-10-4-12-14-3-6-13-0$ & $1-8-13-20-16-13-9-5$ & 119.3 \\
\hline & & $0-5-11-9-8-15-7-1-0$ & $9-4-10-15-9-10-6-5$ & \\
\hline 120 & 1 & $\begin{array}{r}\text { O-6-13-10-4- } 12-14-3-5-11- \\
9-8-15-7-1-\mathrm{O}\end{array}$ & $\begin{array}{r}10-5-0-7-12-17-13-10-6-13- \\
19-14-17-13-10\end{array}$ & 115.8 \\
\hline
\end{tabular}

\subsubsection{The effect of bikes carrying capacity of rebalancing truck (Q)}

In this section, following the study by Erdogan et al. (2014), the effect of vehicle capacity, $Q=\{10,15$, $20,25,30,35,40,45\}$ on the rebalancing routing plan is investigated. When the $100 \%$ target demand is obtained, the optimal solutions of the problem under different truck capacities are accounted in Table 7 and Figure 3.

The outcomes demonstrate that more number of less capacitated vehicles required to accomplish the target demand when compared with large-capacity vehicles. Moreover, large capacity trucks outperform when the rebalancing operation time is sufficient to efficiently use their capacity. The small capacity vehicles perform well without a significant increase in total cost. The large capacity vehicles certainly have more space to easily obtain the target demand, but their operational charges may be quite high as compared to small capacity vehicles. 
Table 7. The optimal solution under different bikes carrying capacity of rebalancing truck

\begin{tabular}{|c|c|c|c|c|}
\hline $\mathrm{T}(\mathrm{min})$ & Truck capacity $(Q)$ & Truck used & Routes & Truckload \\
\hline \multirow[t]{16}{*}{90} & 10 & 2 & O-3-14-12-4-6-13-10-2-7-1-O & $10-6-1-5-10-5-0-8-10-6-5$ \\
\hline & 15 & 2 & O-11-9-8-15-7-1-O & $3-10-15-10-12-7-7$ \\
\hline & & & O13-10-4-14-12-6-3-5-O & $7-2-10-15-10-15-11-7-3$ \\
\hline & 20 & 2 & O-11-9-8-15-7-1-O & $4-10-15-9-10-6-5$ \\
\hline & & & O-13-10-4-12-14-6-3-5-O & $6-1-10-15-20-16-12-9-5$ \\
\hline & 25 & 2 & $\mathrm{O}-13-10-4-12-14-6-3-5-\mathrm{O}$ & $8-4-12-17-22-18-13-9-4$ \\
\hline & & & O-11-9-8-15-7-1-O & $2-9-16-11-12-7-6$ \\
\hline & 30 & 2 & O-13-10-4-12-14-6-3-5-O & $8-4-12-17-22-18-13-9-4$ \\
\hline & & & O-11-9-8-15-7-1-O & $2-9-16-11-12-7-6$ \\
\hline & 35 & 2 & O-13-10-4-12-14-6-3-5-O & $8-4-12-17-22-18-13-9-4$ \\
\hline & & & O-11-9-8-15-7-1-O & $2-9-16-11-12-7-6$ \\
\hline & 40 & 2 & O-13-10-4-12-14-6-3-5-O & $8-4-12-17-22-18-13-9-4$ \\
\hline & & & O-11-9-8-15-7-1-O & $2-9-16-11-12-7-6$ \\
\hline & 45 & 2 & $\mathrm{O}-13-10-4-12-14-6-3-5-\mathrm{O}$ & $8-4-12-17-22-18-13-9-4$ \\
\hline & & & O-11-9-8-15-7-1-O & $2-9-16-11-12-7-6$ \\
\hline & & & O-5-9-8-11-3-14-12-4-6-13-10- & $10-5-10-4-10-6-1-5-10-5-$ \\
\hline \multirow[t]{9}{*}{120} & 10 & 1 & $2-7-1-\mathrm{O}$ & $0-10-10-8-10$ \\
\hline & & & O-1-5-11-9-8-7-2-10-4-13-6-12- & $10-7-2-8-13-7-2-3-10-15-$ \\
\hline & 15 & 1 & $14-3-\mathrm{O}$ & $12-7-15-11-10$ \\
\hline & 20 & 1 & $\begin{array}{r}\text { O-6-13-10-4-12-14-3-5-11-9-8- } \\
15-7-1-\mathrm{O}\end{array}$ & $\begin{array}{r}10-5-0-7-12-17-13-10-6- \\
13-19-14-17-13-10\end{array}$ \\
\hline & 25 & 1 & $\begin{array}{r}\text { O-1-11-9-8-15-7-2-10-4-13-6- } \\
12-14-3-5-\mathrm{O}\end{array}$ & $\begin{array}{l}10-7-14-19-14-15-10-12- \\
20-25-21-16-23-19-15-10\end{array}$ \\
\hline & 30 & 1 & $\begin{array}{r}\text { O-1-11-9-8-15-7-2-10-4-13-6- } \\
12-14-3-5-\mathrm{O}\end{array}$ & $\begin{array}{l}10-7-14-19-14-15-10-12- \\
20-25-21-16-23-19-15-10\end{array}$ \\
\hline & 35 & 1 & $\begin{array}{r}\text { O-1-11-9-8-15-7-2-10-4-13-6- } \\
12-14-3-5-\mathrm{O}\end{array}$ & $\begin{array}{l}10-7-14-19-14-15-10-12- \\
20-25-21-16-23-19-15-10\end{array}$ \\
\hline & 40 & 1 & $\begin{array}{r}\text { O-1-11-9-8-15-7-2-10-4-13-6- } \\
12-14-3-5-\mathrm{O}\end{array}$ & $\begin{array}{l}10-7-14-19-14-15-10-12- \\
20-25-21-16-23-19-15-10\end{array}$ \\
\hline & 45 & 1 & $\begin{array}{r}\text { O-1-11-9-8-15-7-2-10-4-13-6- } \\
12-14-3-5-\mathrm{O}\end{array}$ & $\begin{array}{l}10-7-14-19-14-15-10-12- \\
20-25-21-16-23-19-15-10\end{array}$ \\
\hline
\end{tabular}

The formulated problem can handle heterogeneous fleet with different operational and maintenance costs. For sufficiently large rebalancing operation span for large networks, the optimized fleet size is always better as compared to a predefined number of vehicles to perform the operation. The results in Table 7 and Figure 3 show that a light vehicle with maximum loading capacity of ten bikes performed the same task as compared to other vehicles with only $2.6 \%$ difference in total travelling time. Figure 3 shows that the handling length of faulty bikes decreases with the increasing capacity of a truck because a large-sized vehicle can easily lodge surplus bikes from each station. 


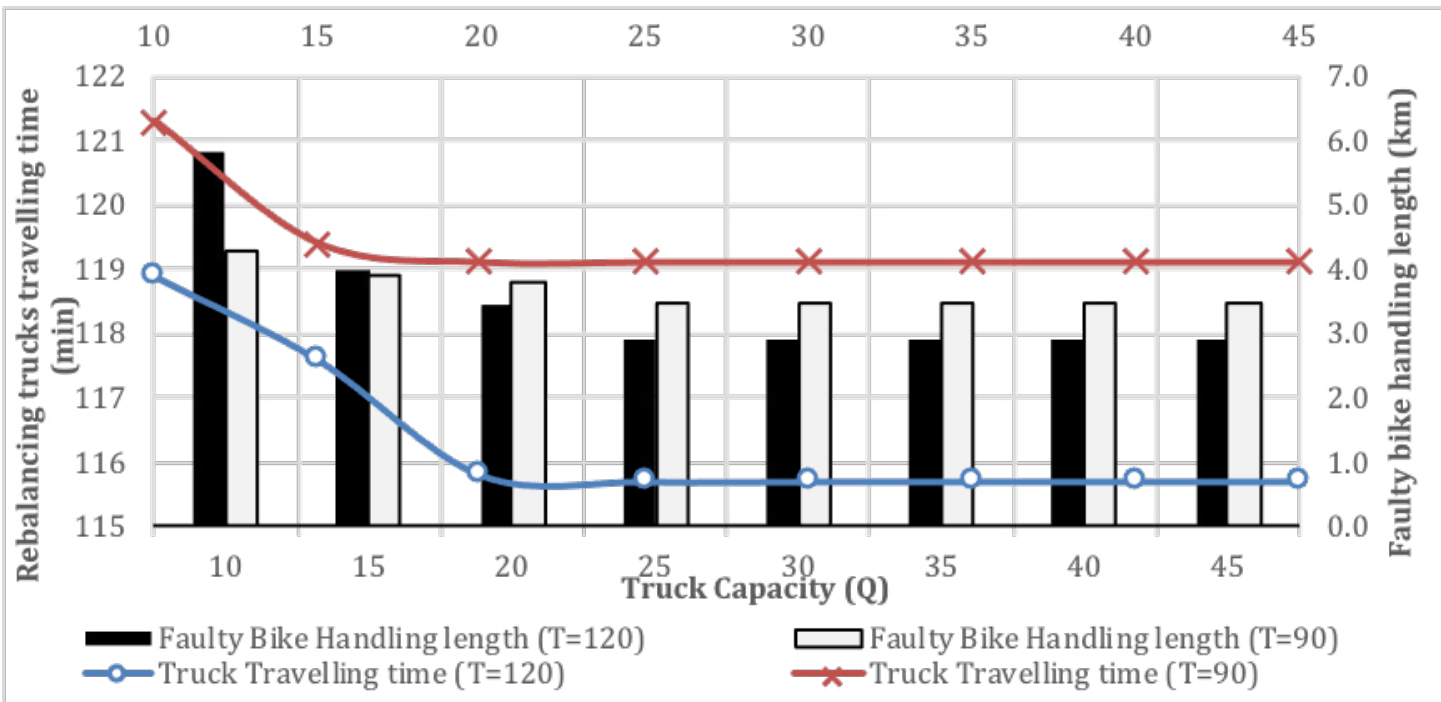

Figure 3. Total travelling time and Faulty bike handling length under the different capacity of rebalancing truck

\subsubsection{The effect of the percentage of faulty bikes}

The presence of faulty bikes affects the routing plan of the rebalancing trucks. The problem is solved under the different percentages of faulty bikes in the network and the results are presented in Table 8.

The results show that with a lesser number of faulty bikes in the network, the rebalancing trucks traverse an easy path to load and unload usable bikes to obtain the target demand at each station. Whereas, with the increase in the percentage of faulty bikes in the network, the rebalancing trucks have to travel longer paths to make space for the faulty bikes. Besides the increase in routing distances, the number of trucks required to obtain the target demand increases as well. 
Table 8. The optimal solutions under different percentage of faulty bikes

\begin{tabular}{|c|c|c|c|c|c|c|c|c|c|c|c|c|c|c|c|c|c|c|c|}
\hline \multicolumn{2}{|c|}{ Station } & \multirow{2}{*}{$\begin{array}{l}1 \\
6\end{array}$} & \multirow{2}{*}{$\begin{array}{c}2 \\
16\end{array}$} & \multirow{2}{*}{$\begin{array}{c}3 \\
18\end{array}$} & \multirow{2}{*}{$\begin{array}{c}4 \\
20\end{array}$} & \multirow{2}{*}{$\begin{array}{l}5 \\
9\end{array}$} & \multirow{2}{*}{$\begin{array}{c}6 \\
14\end{array}$} & \multirow{2}{*}{$\begin{array}{l}7 \\
5\end{array}$} & \multirow{2}{*}{$\begin{array}{l}8 \\
3\end{array}$} & \multirow{2}{*}{$\begin{array}{c}9 \\
20\end{array}$} & \multirow{2}{*}{$\begin{array}{c}10 \\
17\end{array}$} & \multirow{2}{*}{$\begin{array}{l}11 \\
21\end{array}$} & \multirow{2}{*}{$\begin{array}{c}12 \\
17\end{array}$} & \multirow{2}{*}{$\begin{array}{c}13 \\
5\end{array}$} & \multirow{2}{*}{$\begin{array}{c}14 \\
5\end{array}$} & \multirow{2}{*}{$\begin{array}{l}15 \\
12\end{array}$} & \multirow{2}{*}{$\begin{array}{c}\text { TT } \\
(\mathbf{m i n})\end{array}$} & \multirow{2}{*}{$\begin{array}{c}\text { HL } \\
(\mathbf{k m})\end{array}$} & \multirow[t]{2}{*}{$\mathbf{K}$} \\
\hline $\begin{array}{l}\text { FB } \\
(\%) \\
\end{array}$ & So & & & & & & & & & & & & & & & & & & \\
\hline \multirow[t]{3}{*}{0} & $\mathrm{~L}$ & 0 & 0 & 0 & 5 & 0 & 0 & 0 & 0 & 5 & 7 & 6 & 6 & 0 & 0 & 0 & 105.6 & 0 & 1 \\
\hline & $\mathrm{U}$ & 4 & 0 & 4 & 0 & 5 & 5 & 5 & 6 & 0 & 0 & 0 & 0 & 5 & 5 & 0 & & & \\
\hline & $\mathrm{FB}$ & 0 & 0 & 0 & 0 & 0 & 0 & 0 & 0 & 0 & 0 & 0 & 0 & 0 & 0 & 0 & & & \\
\hline \multirow[t]{3}{*}{5} & $\mathrm{~L}$ & 0 & 0 & 0 & 5 & 0 & 0 & 0 & 0 & 5 & 7 & 6 & 6 & 0 & 0 & 0 & 109.6 & 1.4 & 1 \\
\hline & $\mathrm{U}$ & 4 & 0 & 4 & 0 & 5 & 5 & 5 & 6 & 0 & 0 & 0 & 0 & 5 & 5 & 0 & & & \\
\hline & $\mathrm{FB}$ & 1 & 0 & 0 & 0 & 2 & 0 & 1 & 0 & 0 & 0 & 0 & 0 & 0 & 0 & 0 & & & \\
\hline \multirow[t]{3}{*}{10} & $\mathrm{~L}$ & 0 & 0 & 0 & 5 & 0 & 0 & 0 & 0 & 7 & 7 & 6 & 4 & 0 & 0 & 0 & 113.8 & 2.4 & 1 \\
\hline & $\mathrm{U}$ & 4 & 0 & 4 & 0 & 5 & 5 & 5 & 6 & 0 & 0 & 0 & 0 & 5 & 5 & 0 & & & \\
\hline & $\mathrm{FB}$ & 2 & 0 & 0 & 0 & 2 & 0 & 1 & 0 & 0 & 1 & 0 & 0 & 1 & 0 & 1 & & & \\
\hline \multirow[t]{3}{*}{15} & $\mathrm{~L}$ & 0 & 0 & 0 & 5 & 0 & 0 & 0 & 0 & 5 & 7 & 7 & 4 & 0 & 0 & 1 & 116.8 & 3.3 & 1 \\
\hline & $\mathrm{U}$ & 4 & 0 & 4 & 0 & 5 & 5 & 5 & 6 & 0 & 0 & 0 & 0 & 5 & 5 & 0 & & & \\
\hline & $\mathrm{FB}$ & 2 & 0 & 0 & 0 & 2 & 0 & 2 & 0 & 0 & 2 & 1 & 0 & 1 & 0 & 1 & & & \\
\hline \multirow[t]{3}{*}{20} & $\mathrm{~L}$ & 0 & 0 & 0 & 5 & 0 & 0 & 0 & 0 & 5 & 7 & 6 & 6 & 0 & 0 & 0 & 122.6 & 5.6 & 2 \\
\hline & $\mathrm{U}$ & 4 & 0 & 4 & 0 & 5 & 5 & 5 & 6 & 0 & 0 & 0 & 0 & 5 & 5 & 0 & & & \\
\hline & $\mathrm{FB}$ & 2 & 0 & 3 & 0 & 2 & 0 & 2 & 0 & 0 & 1 & 1 & 0 & 3 & 0 & 1 & & & \\
\hline \multirow[t]{3}{*}{25} & $\mathrm{~L}$ & 0 & 0 & 0 & 5 & 0 & 0 & 0 & 0 & 5 & 7 & 6 & 6 & 0 & 0 & 0 & 126.6 & 7.6 & 2 \\
\hline & $\mathrm{U}$ & 4 & 0 & 4 & 0 & 5 & 5 & 5 & 6 & 0 & 0 & 0 & 0 & 5 & 5 & 0 & & & \\
\hline & $\mathrm{FB}$ & 3 & 0 & 4 & 0 & 2 & 0 & 3 & 0 & 0 & 0 & 1 & 0 & 4 & 1 & 1 & & & \\
\hline 30 & $\mathrm{~L}$ & 0 & 0 & 0 & 5 & 0 & 0 & 0 & 0 & 5 & 7 & 6 & 6 & 0 & 0 & 0 & 130.6 & 10.3 & 2 \\
\hline & $\mathrm{U}$ & 4 & 0 & 4 & 0 & 5 & 5 & 5 & 6 & 0 & 0 & 0 & 0 & 5 & 5 & 0 & & & \\
\hline & $\mathrm{FB}$ & 5 & 0 & 6 & 1 & 1 & 0 & 3 & 0 & 0 & 0 & 1 & 0 & 4 & 1 & 1 & & & \\
\hline 35 & $\mathrm{~L}$ & 0 & 0 & 0 & 5 & 0 & 0 & 0 & 0 & 5 & 7 & 6 & 6 & 0 & 0 & 0 & 134.6 & 12.4 & 2 \\
\hline & $\mathrm{U}$ & 4 & 0 & 4 & 0 & 5 & 5 & 5 & 6 & 0 & 0 & 0 & 0 & 5 & 5 & 0 & & & \\
\hline & $\mathrm{FB}$ & 9 & 0 & 6 & 1 & 1 & 0 & 3 & 0 & 0 & 0 & 1 & 0 & 4 & 1 & 1 & & & \\
\hline 40 & $\mathrm{~L}$ & 0 & 0 & 0 & 7 & 0 & 0 & 0 & 0 & 5 & 7 & 6 & 4 & 0 & 0 & 0 & 139.4 & 8.5 & 2 \\
\hline & $\mathrm{U}$ & 4 & 0 & 4 & 0 & 5 & 5 & 5 & 6 & 0 & 0 & 0 & 0 & 5 & 5 & 0 & & & \\
\hline & $\mathrm{FB}$ & 4 & 0 & 4 & 1 & 5 & 1 & 3 & 0 & 2 & 3 & 3 & 0 & 1 & 1 & 2 & & & \\
\hline
\end{tabular}

Note: FB: faulty bikes in the system; L: loading from the station; U: unloading at the station; TT: total travelling time of rebalancing trucks; HL: handling length of faulty bikes; K: number of trucks used for rebalancing. 


\subsubsection{The effect of shifting faulty bikes to closer stations}

To investigate the effect of faulty bikes shifting to their closer stations, the problem is solved for both shifting faulty bikes to their closest and model determined stations and the results are accounted in Table 9 .

Table 9. Optimal solutions under different target station scenarios of faulty bikes

\begin{tabular}{cccc}
\hline Faulty bike shifting & Total travelling time $(\mathbf{m i n})$ & Handling length $\mathbf{( k m )}$ & Vehicle operation cost $(\mathbf{R M B})$ \\
\hline Closer station & 118.4 & 2.9 & 71.6 \\
Model determined & 115.8 & 3.7 & 70.2 \\
\hline
\end{tabular}

Table 9 shows that for the former scenario, the decrease in the handling length of the faulty bikes is $21.4 \%$ as compared to shifting them to the model determined station. However, the increase in rebalancing vehicle's travelling time is $2.3 \%$. Also, the increase in the total operation cost is $2 \%$ for the closer station shifting scenario. Furthermore, the difference in cost can be several hundred RMBs for a real size problem as the size of the problem under consideration is very small.

\subsection{Model application to real instances}

The proposed model is tested using sets of real instances used by Liu et al. (2018) and the results are presented in Table 10.

The results show that the formulation proposed in this study outperforms for small and mediumsize networks. However, the solution time increases exponentially for large-sized problems. Therefore, solution algorithms may be developed to solve large-size problems in future studies.

The results are compared with the best results from Liu et al. (2018) without taking faulty bikes into account. The comparison shows that the presented formulation is quite efficient in solving the problem for all three scenarios. The longer solution time for the formulation presented by Liu et al. (2018) is mainly due to the consideration of time interval in the decision variables.

Table 10. Best results for real instances and comparison with CPLEX solution of Liu et al. (2018)

\begin{tabular}{cccccccc}
\hline \multirow{2}{*}{ Stations } & & & & \multicolumn{2}{c}{ This study } & \multicolumn{2}{c}{ Liu et al. (2018) } \\
\cline { 5 - 8 } & $|D|$ & Vehicle Case & Faulty Bikes & CPU (sec) & $\begin{array}{c}\text { Opt. Gap } \\
(\%)\end{array}$ & CPU (sec) & $\begin{array}{c}\text { Opt. Gap } \\
(\%)\end{array}$ \\
\hline 10 & 1 & 20 & 5 & 0.62 & 0.01 & 398 & 0.01 \\
42 & 1 & 20 & 10 & 410 & 0.01 & 7200 & 19.65 \\
78 & 1 & 20,20 & 15 & 3600 & 2.87 & 7200 & 61.18 \\
\hline
\end{tabular}




\section{Discussion and conclusions}

A brilliant, emission-free and simple solution to the problem of urban congestion, bike-sharing systems is viewed as an essential component of future environmental-friendly multimodal transport. FFBS is widely accepted as an efficient, healthy, and green individual travel mode and has been extensively validated by several studies. The specific features of FFBS facilitate travelers to pick up and drop off the hired bikes without visiting a docking station. However, to maintain better service quality, the sharing-bike operators face various operation challenges. The key problem is to ensure the availability of shared-bikes at various locations to fulfill the users' demand. The uneven flow patterns within the city create an imbalance at various locations. To restore the desired balance, the operators deploy rebalancing trucks to solve this imbalance problem in the system.

Another problem is the presence of faulty bikes in the system. Faulty bikes cause serious safety issues for the users besides other problems. To ensure the suitability of the innovative bikes, a comprehensive mechanism is presented in this study to simultaneously solve the issue of faulty bikes besides the rebalancing problem within the system. This mechanism is realized by minimizing the total routing cost using optimum fleet size supported by various feasibility constraints presented in Section 4.

The formulated problem can help bike-sharing companies: to obtain the target inventory levels at each station, eliminate defective bikes, and distribute repaired bikes using routine rebalancing operations. The simultaneous operation helps in reducing the total operation cost instead of deploying a separate fleet for faulty bikes.

The numerical studies highlight the following features of the model.

a). A well-structured approach for the collection of faulty bikes is presented. The detected faulty bikes are initially shifted to various stations. The destination station of each faulty bikes is taken as a decision variable. The shifting of a faulty bike to its nearest station reduces the handling cost. However, shifting of a faulty bike to its closer station may increase the total cost of the rebalancing operation. In particular, when a closer station has already optimal bike inventory, or there are excessive numbers of usable bikes. The rebalancing truck traverses extra distances or follows another path to get sufficient space to collect both faulty and extra usable bikes in the former and later scenarios, respectively. The results show that faulty bikes are not necessarily shifted to their closer stations in an optimal solution. Besides the collection of faulty bikes at the depot, the presented model defines various constraints for the distribution of repaired bikes within the system.

b). The presented model effectively solves the imbalance problem. Useable bikes target demand interval assumed for each station, and the target is obtained with minimum cost. The shortage of bikes at each station is controlled by introducing a penalty cost against the deviation of obtained inventories from the target demand. This helps the operators to obtain the targets under the various percentage of demand tolerance.

c). The rebalancing operation with faulty bikes is performed with optimized fleet size. The unoptimized fleet size increases the operation cost besides other congestion and environmental issues. The presented model facilitates the operators to manage their heterogeneously capacitated vehicles effectively. The results show that an increase in the number of rebalancing truck always increases the total travelling time of all the vehicles. Besides, different capacity vehicles follow different optimal paths. A large-sized vehicle can follow the best path as compared to small-sized vehicles. However, the high operational cost of large-sized vehicles causes an uneconomic solution. Therefore, it is necessary to deploy an optimized fleet for an economic solution instead of using a predefined number of routing trucks. The presented model can manage a heterogeneous fleet by assigning a different base cost to various types of vehicles.

Using CPLEX solver, the formulated model is demonstrated through various scenarios and the 
corresponding solutions are presented. The model gives exaction solutions for small-sized problems in few seconds. However, the model needs to be tested with real data involving several hundred stations. Besides, this model can be extended for dynamic rebalancing with the real situation instead of considering random data.

\section{Acknowledgements}

This research was supported by the National Natural Science Foundation of China (Grant No. 71701045), the Natural Science Foundation of Jiangsu Province of China (Grant No. BK20190371), and the Fundamental Research Funds for the Central Universities (Grant No. 3221002007C3) 


\section{References}

Alvarez-Valdes, R., Belenguer, J. M., Benavent, E., Bermudez, J. D., Muñoz, F., Vercher, E., \& Verdejo, F. (2016). Optimizing the level of service quality of a bike-sharing system. Omega, 62, 163-75.

Benchimol, M., Benchimol, P., Chappert, B., de la Taille, A., Laroche, F., Meunier, F., \& Robinet, L. (2011). Balancing the stations of a self service 'bike hire' system. RAIRO-Operations Research, 45(1), 37-61.

Biehl, A., Ermagun, A., \& Stathopoulos, A. (2018). Community mobility MAUP-ing: A socio-spatial investigation of bikeshare demand in Chicago. Journal of Transport Geography, 66, 80-90.

Borgnat, P., Abry, P., Flandrin, P., Robardet, C., Rouquier, J., \& Fleury, E. (2010). Shared bicylces in a city: A signal processing and data analysis perspective. https://doi.org/10.1142/S0219525911002950

Campbell, C. (2018). The trouble with sharing: China's bike fever has reached saturation point. Retrieved from http://time.com/5218323/china-bicycles-sharing-economy/

Caulfield, B., O’Mahony, M., Brazil, W., \& Weldon, P. (2017). Examining usage patterns of a bikesharing scheme in a medium-sized city. Transportation Research Part A: Policy and Practice, 100, 152-61.

Chang, S., Song, R., He, S., \& Qiu, G. (2018). Innovative bike-sharing in China: Solving faulty bike-sharing recycling problem. Journal of Advanced Transportation. https://doi.org/10.1155/2018/4941029

Chemla, D., Meunier, F., \& Calvo, R. W. (2013). Bike sharing systems: Solving the static rebalancing problem. Discrete Optimization, 10(2), 120-46.

Chen, J., Li, Z., Wang, W., \& Jiang, H. (2018). Evaluating bicycle-vehicle conflicts and delays on urban streets with bike lane and on-street parking. Transportation Letters, 10(1), 1-11.

Contardo, C., Rousseau, L.-M., \& Morency, C. (2012). Balancing a dynamic public bike-sharing system, vol. 4. Montreal: CIRRELT, University of Montreal, Laval University.

Corcoran, J., Li, T., Rohde, D., Charles-Edwards, E., \& Mateo-Babiano, D. (2014). Spatio-temporal patterns of a public bicycle sharing program: The effect of weather and calendar events. Journal of Transport Geography, 41, 292-305.

Dell'Amico, M., Hadjicostantinou, E., Lori, M., \& Novellani, S. (2014). The bike sharing rebalancing problem: Mathematical formulations and benchmark instances. Omega, 45, 7-19.

Du, M., \& Cheng, L. (2018). Better understanding the characteristics and influential factors of different travel patterns in free-floating bike sharing: Evidence from Nanjing, China. Sustainability, 10, 1244.

Erdoğan, G., Laporte, G., \& Calvo, R. W. (2014). The static bicycle relocation problem with demand intervals. European Journal of Operational Research, 238(2), 451-57.

Fishman, E. (2016). Bikeshare: A review of recent literature. Transport Reviews, 36(1), 92-113.

Gu, T., Kim, I., \& Currie, G. (2019). To be or not to be dockless: Empirical analysis of dockless bikeshare development in China. Transportation Research Part A: Policy and Practice, 119, 122-47.

Guo, Y., Li, Z., Wu, Y., \& Xu, C. (2018). Exploring unobserved heterogeneity in bicyclists' red-light running behaviors at different crossing Facilities. Accident Analysis \& Prevention, 115, 118-27.

Ho, S. C., \& Szeto, Y. W. (2014). Solving a static repositioning problem in bike-sharing systems using iterated tabu search. Transportation Research Part E: Logistics and Transportation Review, 69, 180-98.

Hui, Z. (2020). Beijing puts brakes on E-bike sharing, restricts total number of for-hire bikes. Retrived from http://www.globaltimes.cn/content/1066602.shtml.

Ji, Y., Fan, Y., Ermagun, A., Cao, X., Wang, W., \& Das. K. (2016). Public bicycle as a feeder mode to rail transit in China: The role of gender, age, income, trip purpose, and bicycle theft experience. International Journal of Sustainable Transportation, 11(4), 308-317.

Ji, Y., Ma, X., Yang, M., Jin, Y., \& Gao, L. (2018). Exploring spatially varying influences on metro- 
bikeshare transfer: A geographically weighted poisson regression approach. Sustainability, 10, 1526.

Jiménez, P., Nogal, M., Caulfield, B., \& Pilla, F. (2016). Perceptually important points of mobility patterns to characterize bike sharing systems: The Dublin case. Journal of Transport Geography, 54, 228-39.

Kaspi, M., Raviv, T., \& Tzur, M. (2016). Detection of unusable bicycles in bike-sharing systems. Omega, 65, 10-16.

Kaspi, M., Raviv, T., \& Tzur, M. (2017). Bike-sharing systems: User dissatisfaction in the presence of unusable bicycles. IISE Transactions, 49(2), 144-58.

Kloimüllner, C., Papazek, P., Hu, B., \& Raidl, G. R. (2015). A cluster-first route-second approach for balancing bicycle sharing systems. (pp. 439-46). Lecture Notes in Computer Science, 9520. https:// doi.org/10.1007/978-3-319-27340-2_55

Lan, J., Ma, Y., Zhu, D., Mangalagiu, D., \& Thornton, T. F. (2017). Enabling value co-creation in the sharing economy: The case of mobike. Sustainability, 9(9), 1504.

Lazo, L. (2018, July 1). Theft and destruction of dockless bikes a growing problem. The Washington Post. Retrieved from https://www.washingtonpost.com/news/dr-gridlock/wp/2018/07/01/theft-and-destruction-of-dockless-bikes-a-growing-problem/

Liu, Y., Szeto, W. Y., \& Ho, S. C. (2018). A static free-floating bike repositioning problem with multiple heterogeneous vehicles, multiple depots, and multiple visits. Transportation Research Part C: Emerging Technologies, 92(May), 208-42.

Ma, L., Zhang, X., \& Wang, G. S. (2017). Identifying the reasons why users in China recommend bike apps. International Journal of Market Research, 59(6), 767-86.

Médard de Chardon, C., \& Caruso, G.(2015). Estimating bike-share trips using station level data. Transportation Research Part B: Methodological, 78, 260-279. https://doi.org/10.1016/j.trb.2015.05.003

Meddin, R., \& DeMaio, P. (2019). The bike-sharing world map. Retrieved from www.bikesharingmap. com

Möhlmann, M. (2015). Collaborative consumption: Determinants of satisfaction and the likelihood of using a sharing economy option again. Journal of Consumer Behavior, 14(3), 193-207.

Montoliu, R. (2012). Discovering mobility patterns on bicycle-based public transportation system by using probabilistic topic models. In P Novais, K. Hallenborg, D. Tapia, \& J. Rodríguez (Eds.) Ambient intelligence - Software and applications, advances in intelligent and soft computing, vol 153 (pp. 145-53) Springer, Berlin: Springer.

Pal, A., \& Zhang, Y. (2017). Free-floating bike sharing: Solving real-life large-scale static rebalancing problems. Transportation Research Part C: Emerging Technologies, 80, 92-116.

Parkes, S. D., Marsden, G., Shaheen, S. A., \& Cohen, A. P. (2013). Understanding the diffusion of public bikesharing systems: Evidence from Europe and North America. Journal of Transport Geography, 31, 94-103.

Rainer-Harbach, M., Papazek, P., Hu, B., \& Raidl, G. R. (2013). Balancing bicycle sharing systems: A variable neighborhood search approach. Lecture Notes in Computer Science, 7832, 121-32.

Raviv, T., Tzur, M., \& Forma, I. A. (2013). Static repositioning in a bike-sharing system: Models and solution approaches. EURO Journal on Transportation and Logistics, 2(3), 187-229.

Sarkar, A., Lathia, N., \& Mascolo, C. (2015). Comparing cities' cycling patterns using online shared bicycle maps. Transportation, 42(4), 541-59.

Schuijbroek, J., Hampshire, R. C., \& van Hoeve, W. J. (2017). Inventory rebalancing and vehicle routing in bike sharing systems. European Journal of Operational Research, 257(3), 992-1004.

Shaheen, S. A., Guzman, S., \& Zhang, H. (2010). Bikesharing in Europe, the Americas, and Asia. Transportation Research Record: Journal of the Transportation Research Board, 2143(1), 159-67. 
Shaheen, S. A., Zhang, H., Martin, E., \& Guzman, S. (2011). China's Hangzhou public bicycle. Transportation Research Record: Journal of the Transportation Research Board, 2247(1), 33-41.

Shaheen, S., \& Chan, N. (2016). Mobility and the sharing economy: Potential to facilitate the first- and last-mile public transit Connections. Built Environment, 42(4), 573-588.

Shui, C. S., \& Szeto, W. Y. (2018). Dynamic green bike repositioning problem - A hybrid rolling horizon artificial bee colony algorithm approach. Transportation Research Part D: Transport and Environment, 60, 119-36.

Sun, Y. (2018). Sharing and riding: How the dockless bike sharing scheme in China shapes the city. Urban Science, 2(3), 68.

Taylor, A. (2018, March). Bike share oversupply in China: Huge piles of abandoned and broken bicycles. The Atlantic. Retrieved from https:/www.theatlantic.com/photo/2018/03/bike-share-oversupply-in-china-huge-piles-of-abandoned-and-broken-bicycles/556268/\#img03

Usama, M., Shen, Y., \& Zahoor, O. (2019). Toward an energy efficient solution for bike-sharing rebalancing problems: A battery electric vehicle scenario. Energies, 12(13), 2503.

Usama, M., Zahoor, O., Bao, Q., Liu, Z., \& Shen, Y. (2019). Dockless bike-sharing rebalancing problem with simultaneous faulty bike recycling. Proceedings of the 19th COTA International Conference of Transportation Professionals, 4963-4974.

Vogel, P., Greiser, T., \& Mattfeld, D. C. (2011). Understanding bike-sharing systems using data mining: Exploring activity patterns. Procedia - Social and Behavioral Sciences, 20, 514-23.

Wang, C., Xu, C., Xia, J., \& Qian, Z. (2017). Modeling faults among e-bike-related fatal crashes in China. Traffic Injury Prevention, 18(2), 175-81.

Wang, Y., \& Szeto, W. Y. (2018). Static green repositioning in bike sharing systems with broken bikes. Transportation Research Part D: Transport and Environment, 65(September), 438-457.

Yan, A. (2017, March 1). Thousands of bike-sharing scheme cycles seized in Shanghai, South China Morning Post. Retrived from https:/www.scmp.com/news/china/society/article/2075091/thousands-bike-sharing-scheme-cycles-seized-shanghai.

Yin, J., Qian, L., \& Shen, J. (2018). From value co-creation to value co-destruction? The case of dockless bike sharing in China. Transportation Research Part D: Transport and Environment, 71, 169-185.

Zhang, D., Yu, C., Desai, J., Lau, H. Y. K., \& Srivathsan, S. (2017). A time-space network flow approach to dynamic repositioning in bicycle sharing systems. Transportation Research Part B: Methodological, 103, 188-207.

Zhang, S., Xiang, G., \& Huang, Z. (2018). Bike-sharing static rebalancing by considering the collection of bicycles in need of repair. Journal of Advanced Transportation, 2018, 1-18.

Zhang, Y, Brussel, M G. B., Thomas, T. \& van Maarseveen, M. F. A. M. (2018). Mining bike-sharing travel behavior data: An investigation into trip chains and transition activities. Computers, Environment and Urban Systems, 69, 39-50.

Zhang, Y., \& Mi, Z. (2018). Environmental benefits of bike sharing: A big data-based analysis. Applied Energy, 220(December), 296-301.

Zhong, R., \& Zhang, C. (2018, December 20). Ofo, pioneer of China's bike-sharing boom, is in a crisis. The New York Times. Retrieved from www.nytimes.com/2018/12/20/technology/ofo-bicycle-sharechina.html. 